\title{
Lobar volume reduction surgery: a method of increasing the lung cancer resection rate in patients with emphysema
}

\author{
J G Edwards, D J R Duthie, D A Waller
}

\begin{abstract}
Background-Guidelines on patient selection for lung cancer resection identify a predicted postoperative forced expiratory volume in 1 second $\left(\right.$ ppoFEV $\left._{1}\right)$ of $<40 \%$ as a predictor of high risk. Experience with lung volume reduction surgery suggests that ppoFEV may be underestimated in those with concomitant emphysema. Methods-Anatomical lobectomy was performed in 29 patients with a resectable lung cancer within a poorly perfused, hyperinflated emphysematous lobe identified by radionuclide perfusion scintigraphy and computed tomographic scanning. Perioperative changes in spirometric parameters at 3 months were compared in $\mathbf{1 4}$ patients (group A) of mean age 69 years (range 48-78) with ppoFEV $1<40 \%$ (mean (SD) $31.4(7) \%$ ) and 15 patients (group B) with ppoFEV $>40 \%$ (mean (SD) 47 (5)\%). The correlation between predicted and

complications, ${ }^{4}$ with a predicted postoperative forced expiratory volume in 1 second $\left(\right.$ ppoFEV $\left._{1}\right)$ measurement of less than $40 \%$ predicted associated with an unacceptable risk of postoperative morbidity. ${ }^{5}$ These values have previously guided our patient selection. However, increased understanding of lung volume reduction surgery (LVRS) has shown that resection of relatively functionless emphysematous lung may actually improve lung function. ${ }^{67}$ We have therefore applied the principles of selection for LVRS to those patients presenting with resectable NSCLC and moderate to severe emphysema. We report our initial experience with this cohort of patients undergoing lobectomy for NSCLC who, as a result, effectively have undergone LVRS. Our objectives were to assess whether lung function changes uniformly with lobectomy in all patients, whether the currently used predictive methods are accurate in all cases, and whether the cut off point of $40 \%$ ppoFEV $_{1}$ is clinically binding.
\end{abstract} actual postoperative $\mathrm{FEV}_{1}$ was also assessed.

Results-In group B there was a significant perioperative reduction in $\mathrm{FEV}_{1}(\mathrm{p}=0.01)$ but in group $A \mathrm{FEV}_{1}$ did not change significantly after lobectomy $(p=0.87)$; mean difference in perioperative change between groups $A$ and B $331 \mathrm{ml}$ (95\% CI 150 to 510). Despite the difference in $\mathrm{ppoFEV}_{1}$ between the groups, there was no difference in actual $\mathrm{FEV}_{1}$ at 3 months. In-hospital mortality was $14 \%$ in group $A$ and zero in group $B$, but at a median follow up of 12 (range 6-40) months there was no difference in survival between the groups.

Conclusions-Selection for lung cancer resection in patients with emphysema using standard calculations of ppoFEV may be misleading. The effect of lobar volume reduction allows for an extension of the selection criteria.

(Thorax 2001;56:791-795)

Keywords: lobar volume reduction surgery; lung cancer; patient selection

sented at the Annual Winter Meeting of the

British Thoracic Society in

London on 13-15 December

1999.

Correspondence to: Mr D A Waller debra.grew@uhl-tr.nhs.uk

Received 9 January 2001 Returned to authors 26 March 2001

Revised version received

4 June 2001

Accepted for publication

5 July 2001

Increasing the resection rate is fundamental to improving outcome in non-small cell lung cancer (NSCLC). The suboptimal resection rate in the UK, currently around $10 \%,{ }^{12}$ may be partly attributed to the assessment of inoperability in the large number of patients who have both lung cancer and concomitant emphysema. ${ }^{3}$ Prediction of postoperative respiratory function has been found to be a predictor of pulmonary

\section{Methods}

All patients were referred primarily for resection of a newly diagnosed NSCLC rather than for treatment of emphysema. Resectability was confirmed by computed tomographic (CT) scanning and, where indicated, cervical mediastinoscopy. Simple spirometric measurements of $\mathrm{FEV}_{1}$ and forced vital capacity (FVC) were made as part of an assessment of operability. Patients did not undergo routine plethysmography.

The preoperative COPD index ${ }^{8}$ was derived for each patient using the following formula:

COPD index $=\mathrm{FEV}_{1}(\%$ predicted $)+$ $\left(\mathrm{FEV}_{1} / \mathrm{FVC}(\mathrm{lit})\right)$

Predicted postoperative $\mathrm{FEV}_{1}$ (ppoFEV ${ }_{1}$ ) was also derived for each patient using the following formula estimating the number of pulmonary segments to be resected ${ }^{9}$ :

ppoFEV $_{1}=$ preoperative $\mathrm{FEV}_{1} \times[1-$ $(b-n)] /(42-n)$ where $b=$ number of segments to be resected and $n=$ number of obstructed segments of that lobe.

In patients whose ppoFEV $\mathrm{F}_{1}$ was less than $60 \%$ predicted, quantitative radionuclide scintigraphy was performed to estimate the function of emphysematous areas of the lung. These were correlated with anatomical findings on the CT scan.

Lung resection was only attempted in patients with a ppoFEV ${ }_{1}$ of less than $40 \%$ predicted if the tumour was resectable by lobectomy, the target lobe was emphysematous and contributed less than $10 \%$ of overall 
Table 1 Patient characteristics and perioperative results

\begin{tabular}{lllllc}
\hline & $\begin{array}{l}\text { Group } A \\
(n=14)\end{array}$ & $\begin{array}{l}\text { Group } B \\
(n=15)\end{array}$ & $\begin{array}{l}\text { Mean } \\
\text { difference }\end{array}$ & $95 \%$ CI & p value \\
\hline $\begin{array}{lllll}\text { Age (years) } \\
\text { Male:female }\end{array}$ & $\begin{array}{l}68.9(48-78) \\
9: 5\end{array}$ & $\begin{array}{l}71.4(55-79) \\
12: 3\end{array}$ & 2.47 & -3.8 to 8.7 & 0.42 \\
$\begin{array}{l}\text { Postoperative stay (days) } \\
\text { 30 day mortality }\end{array}$ & $\begin{array}{l}12.7(6-36) \\
\text { Survival (days) }\end{array}$ & $\begin{array}{l}13.2(6-39) \\
0\end{array}$ & 0.5 & -7 to 8.1 & 0.89 \\
\hline
\end{tabular}

Values are mean (range).

perfusion, and there was evidence of hyperinflation on radiological assessment.

PERIOPERATIVE MANAGEMENT

General anaesthesia was induced with intravenous propofol and fentanyl and maintained by a target controlled infusion of propofol. Neuromuscular blockade was maintained by intravenous vecuronium in increments as required. Ventilation was carried out via a double lumen endobronchial tube with $10 \mathrm{ml} / \mathrm{kg}$ oxygen in air. Before surgery a thoracic epidural tube was inserted between T5 and T8 and an infusion of fentanyl $5 \mu \mathrm{g} / \mathrm{ml}$ in bupivacaine $0.1 \%$ was commenced. During single lung ventilation, while resection was performed, tidal volumes were reduced to keep peak inflation pressures below $40 \mathrm{~cm} \mathrm{H}_{2} \mathrm{O}$ and ventilation frequency was adjusted to keep end tidal carbon dioxide tensions below $6 \%$. In the event of intraoperative arterial oxygen desaturation, oxygen was insufflated into the operative lung with the addition of continuous positive airway pressure if required. Surgical resection comprised anatomical lobectomy in all patients performed via muscle sparing posterolateral thoracotomy or by video assisted thoracoscopy ${ }^{10}$ where possible. Systematic lymph node dissection ${ }^{11}$ was employed and sleeve resections performed for hilar lymph node involvement of main bronchi. The endobronchial tube was removed in the operating theatre. Patients were than transferred to a high dependency unit via a recovery area, breathing spontaneously using a low volume mask delivering $40 \%$ inspired oxygen. Early postoperative mobilisation was facilitated by patient controlled epidural analgesia, early chest physiotherapy, and the early use of flutter valve drainage bags (Portex, Hythe, UK). ${ }^{12}$

Patients were reviewed routinely at 2,6 , and 12 weeks and simple spirometric measurements of $\mathrm{FEV}_{1}$ and FVC were performed.

\section{STATISTICAL ANALYSIS}

The patients were arbitrarily analysed in two distinct groups: group $\mathrm{A}$ in whom ppoFEV was less than $40 \%$ predicted and group $B$ in whom ppoFEV $_{1}$ was greater than $40 \%$ predicted. Paired and independent sample $t$ tests were used to compare perioperative changes in $\mathrm{FEV}_{1}$ and differences between groups $\mathrm{A}$ and $\mathrm{B}$. A Bland-Altman plot $^{13}$ was used to test the accuracy of the standard method of ppoFEV calculation. Survival curves were estimated according to the Kaplan-Meier method and differences between groups assessed by $\log$ rank analysis. Intergroup differences in categorical variables were assessed by $\chi^{2}$ analysis. The statistical software package SPSS for Windows 9.0 (SPSS Inc, Chicago, USA) was used for analysis.

\section{Results}

PATIENT CHARACTERISTICS

There were no significant differences in the age/sex distributions of the two groups (table 1). In all patients in whom radionuclide scintigraphy was performed, the tumour was situated in the zone of least perfusion. One lower lobectomy was performed and all other patients underwent upper lobectomy. Three lobectomies were performed thoracoscopically (one in group A, two in group B); all others were performed by thoracotomy including two sleeve resections (one in each group). There was no difference in postoperative hospital stay between the two groups. Major morbidity included respiratory complications (bronchopneumonia, empyema) which occurred in two patients in each group, and gastrointestinal perforation which occurred in two patients in group A. In-hospital mortality was higher in group A (two patients (14\%) who were ventilated for postoperative bronchopneumonia). There was no difference in median survival. The overall pathological stage distribution was 15 patients in stage I, nine in stage II, four in stage IIIa, and one in stage IIIb (an ipsilateral satellite nodule). There was no significant difference in stage distribution between the two groups. All lobes removed showed histological evidence of centrilobular emphysema. Survival at 6 months was directly related to TNM stage $(p=0.02)$ but not to preoperative $\mathrm{FEV}_{1}(\mathrm{p}=0.36)$. One year survival was found to be unrelated to either TNM stage $(p=0.16)$, preoperative $\mathrm{FEV}_{1}(\mathrm{p}=0.27)$, or $\operatorname{ppoFEV}_{1}(p=0.77)$.

PERIOPERATIVE CHANGES IN RESPIRATORY FUNCTION

Overall, there was a significant perioperative decrease in $\mathrm{FEV}_{1}$ (mean difference $116 \mathrm{ml}$, $95 \%$ CI 2 to 231, $\mathrm{p}=0.04$; fig 1, table 2). In group $\mathrm{B}$ there was a significant perioperative

Table 2 Perioperative changes in pulmonary function

\begin{tabular}{|c|c|c|c|c|c|}
\hline & Group $A$ & Group B & Mean difference & $95 \% C I$ & p value \\
\hline Preoperative FVC (\% pred) & $71.8(63-93)$ & $79.3(66-97)$ & 7.5 & -0.5 to 15.4 & 0.06 \\
\hline Postoperative FVC (\% pred) & $64.4(40-84)$ & $65(46-88)$ & 0.6 & -12 to 13.1 & 0.93 \\
\hline Preoperative $\mathrm{FEV}_{1}$ (1) & $1.0(0.68-1.5)$ & $1.63(0.9-2.65)$ & 0.62 & 0.33 to 0.92 & 0.0001 \\
\hline Postoperative FEV (1) & $1.02(0.65-1.25)$ & $1.31(0.75-2.3)$ & 0.29 & -0.001 to 0.59 & 0.06 \\
\hline Perioperative change in $\mathrm{FEV}_{1}(\mathrm{l})$ & $0.06(-0.37-0.34)$ & $-0.27(-0.54-0)$ & 0.33 & 0.15 to 0.51 & 0.001 \\
\hline $\mathrm{FEV}_{1} / \mathrm{FVC}(\%)$ & $44(27-76)$ & $57(49-87)$ & 0.13 & 0.02 to 0.24 & 0.03 \\
\hline Predicted postoperative $\mathrm{FEV}_{1}$ (\% pred) & $31.4(16-39)$ & $47.3(40-56)$ & 15.9 & 11.2 to 20.6 & 0.0001 \\
\hline Actual postoperative $\mathrm{FEV}_{1}$ (\% pred) & $41.5(18-57)$ & $46.6(30-61)$ & 5.0 & -4.0 to 14.0 & 0.26 \\
\hline
\end{tabular}

Values are mean (range)

$\mathrm{FVC}=$ forced vital capacity; $\mathrm{FEV}_{1}=$ forced expiratory volume in 1 second. 


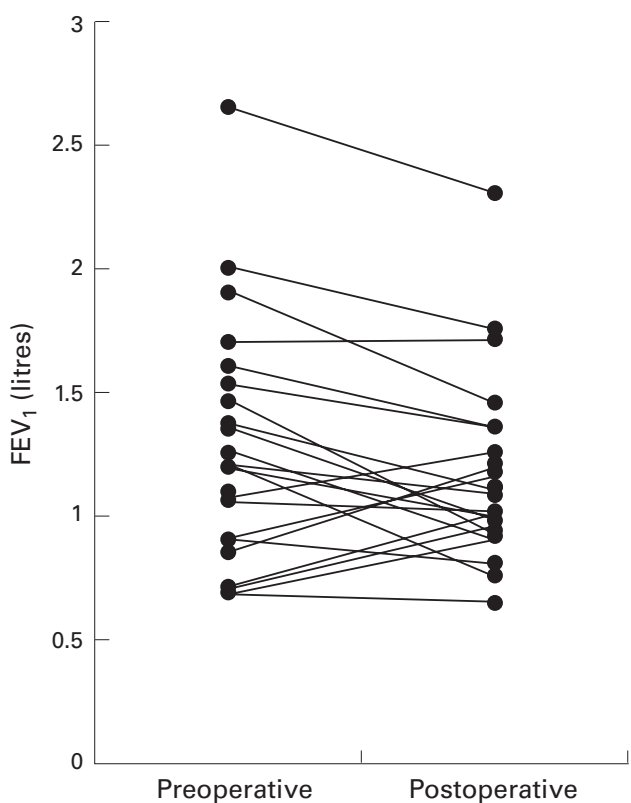

Figure 1 Perioperative changes in FEV .

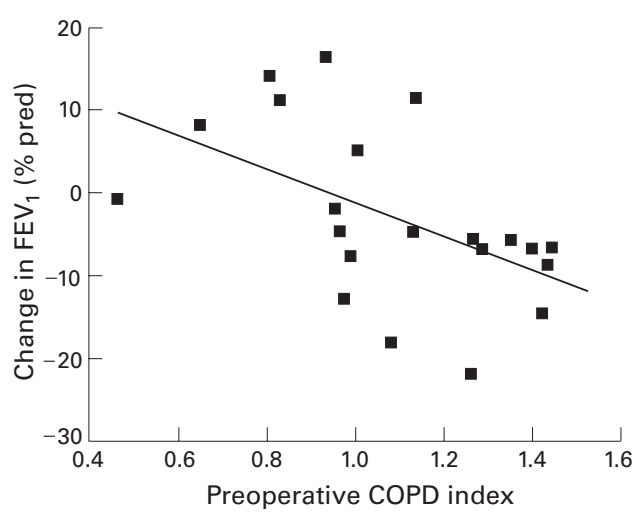

Figure 2 Prediction of perioperative change in $\mathrm{FEV}$, by $C O P D$ index $(r=-0.53, p=0.014)$.

decrease in $\mathrm{FEV}_{1}$ (mean difference $270 \mathrm{ml}$, 95\% CI 170 to $380, \mathrm{p}=0.001$ ) and FVC (mean difference $440 \mathrm{ml}, 95 \%$ CI 80 to $800, \mathrm{p}=0.02$ ), but not in group A where lobectomy resulted in no significant change in either $\mathrm{FEV}_{1}$ (mean difference $60 \mathrm{ml}, 95 \% \mathrm{CI}-20$ to 110 ) or FVC (mean difference $280 \mathrm{ml}, 95 \% \mathrm{CI}-140$ to 700). There was a significant difference between groups $A$ and $B$ in the mean perioperative change in $\mathrm{FEV}_{1}$ (mean difference $331 \mathrm{ml}, 95 \%$ CI 150 to 510). Although there was a significantly lower mean $\mathrm{FEV}_{1}$ in group $\mathrm{A}$ than in group B before surgery, at 3 months after lobectomy there was no significant difference in $\mathrm{FEV}_{1}$ between the groups. There was a significant correlation between the perioperative change in $\mathrm{FEV}_{1}$ and the preoperative COPD index $(r=-0.53, \mathrm{p}=0.01$, fig 2$)$.

PREDICTION OF POSTOPERATIVE RESPIRATORY FUNCTION

Predicted postoperative $\mathrm{FEV}_{1}$ was significantly lower than the actual $\mathrm{FEV}_{1}$ in group $\mathrm{A}$ (mean difference $10.3 \%, 95 \%$ CI 4.9 to 15.6 , $\mathrm{p}=0.002$ ), but there was no significant change in group $\mathrm{B}$ (mean difference $-0.4 \%, 95 \% \mathrm{CI}$ -3.7 to 4.5 , fig 3). A Bland-Altman plot (fig 4)

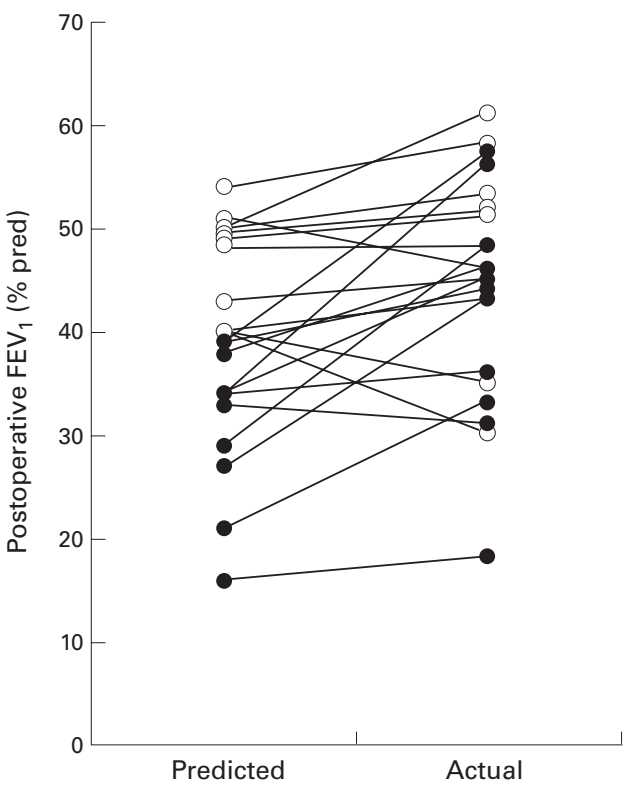

Figure 3 Comparison of predicted and actual postoperative $F E V_{1}$ in patients in group $A(\bullet)$ and group $B$ (O).

shows that the mean discrepancy between actual and predicted $\mathrm{FEV}_{1}$ was greater in group A. In only one patient in group A was the actual postoperative $\mathrm{FEV}_{1}$ less than the ppoFEV .

\section{Discussion}

We have found that lobectomy for NSCLC in patients with poor lung function secondary to emphysema is feasible. Although perioperative risk is increased, subsequent survival is not compromised. We would therefore contend that surgery is preferable to radical radiotherapy in this group of patients. Furthermore, in these patients anatomical lobectomy has been shown to have a therapeutic effect on postoperative respiratory function.

Previous studies have also seen an improvement in pulmonary function in selected patients with severe emphysema undergoing lobectomy for lung cancer. ${ }^{814}$ However, unlike our experience, there were few patients in these series with ppoFEV $\mathrm{F}_{1}$ less than $40 \%$ predicted. In a study of 13 patients a mean perioperative improvement of $3.7 \%$ was noted in predicted $\mathrm{FEV}_{1}{ }^{8}$ and a similar improvement in mean $\mathrm{FEV}_{1}$ of $4 \%$ was found in another small series of 10 patients, ${ }^{14}$ but again in patients with better preoperative respiratory function than ours. We have also demonstrated the use of a COPD index to predict perioperative change in $\mathrm{FEV}_{1}{ }^{8}$

While we are confident in attributing our demonstrated improvement to the effects of surgery, we concede that a small proportion of the effect is due to the optimising of medical treatment for COPD during hospitalisation. There may also be a psychological component to the effect, secondary to increased motivation after successful removal of a lung cancer. To avoid the immediate detrimental effects of surgery, assessment of spirometric parameters was not made before three postoperative months had elapsed. 


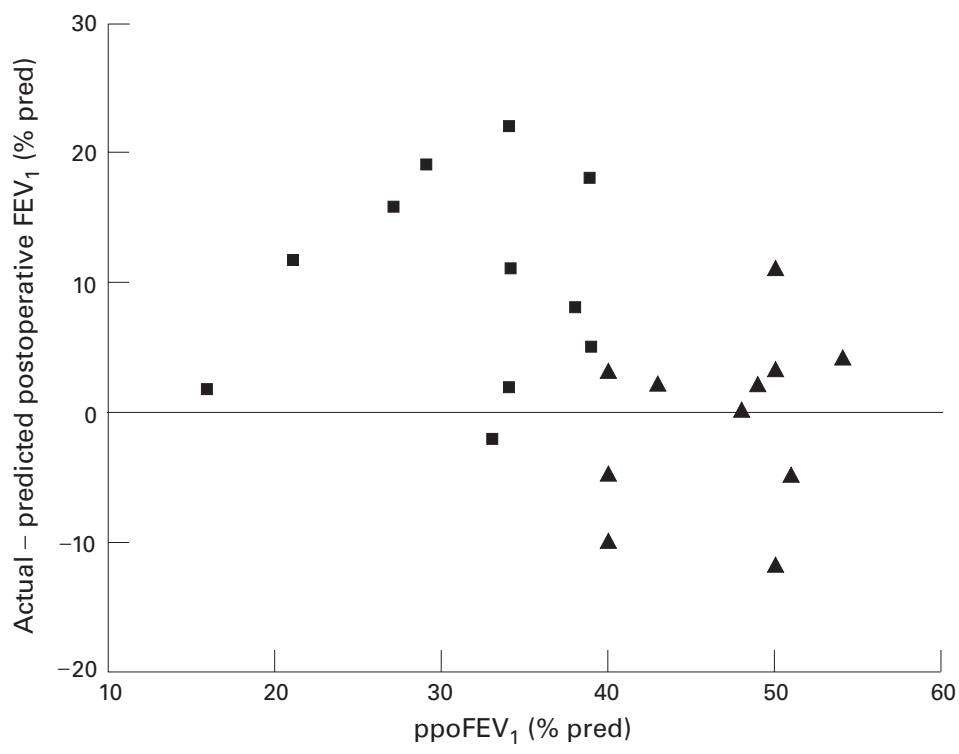

Figure 4 Bland-Altman plot of the effect of predicted postoperative (ppo) FEV on the prediction of actual postoperative $F E V_{1}$ with decreasing ppoFEV in patients in groups $A$ (घ) and $B(\mathbf{\Delta}) ; r=-0.41, p=0.052$. Horizontal line = line of equality.

The estimation of perioperative risk in patients with respiratory dysfunction has focused on the calculation of $\mathrm{ppoFEV}_{1} \cdot{ }^{45} \mathrm{~A}$ value for ppoFEV $_{1}$ below $40 \%$ predicted has been proposed as the lower limit of acceptable risk and this is the reason for our arbitrary selection of this value to divide the patients into two groups. A hazard ratio of 1.46 for every $200 \mathrm{ml}$ decrease in ppoFEV below this value has been calculated. ${ }^{4}$ The most simple method of ppoFEV $_{1}$ calculation is based on a reduction factor proportional to the number of bronchopulmonary segments to be resected. ${ }^{15}$ However, this assumes the function of resected segments to be equivalent to the rest of the lung. It has been recognised that there is a possible source of underestimation if the tumour to be resected is obstructing the airway. A correction for this factor has been proposed. ${ }^{9}$ In our series there were no obstructing tumours, although our calculations of predicted function did not take into account the effect of deflation of the overexpanded thoracic cage, hence our underestimation of postoperative function in those patients with more severe emphysema. Quantitative radionuclide perfusion scintigraphy may give useful information regarding prediction of function after pneumonectomy, ${ }^{16}$ but the information is not in sufficient anatomical detail to predict function after lobectomy.

Extrapolation of selection criteria for LVRS for emphysematous patients with concomitant lung cancer has suggested that both conditions can be treated simultaneously. In two series where malignant pulmonary nodules have been discovered during preoperative investigation for LVRS, subsequent simultaneous LVRS and contralateral lobectomy have been successful. ${ }^{17}{ }^{18}$ Furthermore, anatomical lobectomy has been used successfully for LVRS alone in patients without lung cancer. ${ }^{19}$ The beneficial effects on lung elastic recoil and chest wall mechanics ${ }^{67}$ of resecting a hyperinflated tumour-containing lobe thus outweigh any loss of function, particularly if the lobe is poorly perfused. It is reasonable to assume that lobar LVRS would have a bilateral effect on chest wall mechanics (and therefore a significant respiratory improvement) since some authors have found little difference in the comparative overall benefit of unilateral versus bilateral LVRS..$^{20}$ It is important to emphasise that in this study all patients underwent anatomical lobectomy and no patients underwent any form of sublobar "lung shaving" as is performed in LVRS.

The clinical implication of extending the selection criteria for lung cancer surgery is obviously an increase in the resection rate. In our unit we have operated on 14 patients with ppoFEV ${ }_{1}$ less than $40 \%$ who would otherwise have been denied surgery. This equates to around $7 \%$ of all resections performed over this same time period. In the UK annually about 3000 resections are performed for NSCLC; thus, if our experience was applied nationally, over 200 more patients would undergo resection each year. While perioperative mortality would probably increase as a result of operating on more high risk patients, further work is required to analyse whether longer term overall survival from lung cancer would be improved. We have not found that 1 year survival from surgery in this series is worse in those with poorer preoperative lung function.

In conclusion, consideration of fitness for surgery in lung cancer should acknowledge the effect of lobar LVRS. Current methods of calculation may underestimate prediction of postoperative respiratory function and the cut off

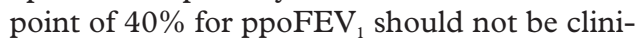
cally binding. Current guidelines ${ }^{21}$ should include an acknowledgement of the effects of surgery in heterogenous emphysema. Lung function does not change uniformly after lobectomy and these patients may even derive early benefit. Further study of durability and related health status changes is required.

1 Fountain S. Surgery for lung cancer. Thorax 1998;53:441. 2 Laroche C, Wells F, Coulden R, et al. Improving surgical resection rate in lung cancer. Thorax 1998;53:445-9.

3 Anonymous. Clinical practice guidelines for the treatment of unresectable non-small-cell lung cancer. Adopted on 16 May 1997 by the American Society of Clinical Oncology. $\mathcal{F}$ Clin Oncol 1997;15:2996-3018.

4 Kearney DJ, Lee TH, Reilly JJ, et al. Assessment of operative isk in patients undergoing lung resection. Importance of predicted pulmonary function. Chest 1994;105:753-9.

5 Markos J, Mullan BP, Hillman DR, et al. Preoperative assessment as a predictor of mortality and morbidity after lung resection. Am Rev Respir Dis 1989;139:902-10.

6 Geddes DM. Lung volume reduction surgery. Thorax 1999; 54(Suppl 2):S14-18

7 Gelb AF, McKenna RJ, Jr., Brenner M, et al. Lung function 4 years after lung volume reduction surgery for emphysema. Chest 1999;116:1608-15.

8 Korst RJ, Ginsberg RJ, Ailawadi M, et al. Lobectomy Korst RJ, Ginsberg RJ, Ailawadi M, et al. Lobectomy
improves ventilatory function in selected patients with improves ventilatory function in selected patien
severe COPD. Ann Thorac Surg 1998;66:898-902.

9 Nakahara K, Monden Y, Ohno K, et al. A method for predicting postoperative lung function and its relation to postoperative complications in patients with lung cancer. Ann Thorac Surg 1984;39:260-5.

10 Walker WS, Carnochan FM, Pugh GC. Thoracoscopic pulmonary lobectomy. Early operative experience and preliminary clinical results. F Thorac Cardiovasc Surg 1993;106: 1111-7.

11 Graham AN, Chan KJ, Pastorino U, et al. Systematic nodal dissection in the intrathoracic staging of patients with nonsmall cell lung cancer. F Thorac Cardiovasc Surg 1999;117: 246-51.

12 Waller D, Edwards J, Rajesh P. Physiological comparison of flutter valve drainage bags and underwater seal systems for postoperative air leaks. Thorax 1999;54:442-3. 
13 Bland J, Altman D. Statistical methods for assessing agreement between two methods of clinical measurement. Lancet $1986 ; \mathrm{i}: 307-10$

14 Carretta A, Zannini P, Puglisi A, et al. Improvement of pulmonary function after lobectomy for non-small cell lung cancer in emphysematous patients. Eur $\mathcal{F}$ Cardio-Thorac Surg 1999;15:602-7.

15 Zeiher BG, Gross TJ, Kern JA, et al. Predicting postoperative pulmonary function in patients undergoing lung resection. Chest 1995;108:68-72.

16 Bolliger C, Wyser C, Roser H, et al. Lung scanning and exercise testing for the prediction of postoperative perfomance in lung resection candidates at increased risk for complications. Chest 1995;108:341-8.

17 DeMeester SR, Patterson GA, Sundaresan RS, et al. Lobectomy combined with volume reduction for patients with lung cancer and advanced emphysema. F Thorac Cardiovasc Surg 1998;115:681-8.

18 McKenna RJ Jr, Fischel RJ, Brenner M, et al. Combined operations for lung volume reduction surgery and lung cancer. Chest 1996;110:885-8.

19 Roue C, Mal H, Sleiman C, et al. Lung volume reduction in patients with severe diffuse emphysema. A retrospective study. Chest 1996;110:28-34

20 Lowdermilk GA, Keenan RJ, Landreneau RJ, et al. Comparison of clinical results for unilateral and bilateral thoracoscopic lung volume reduction. Ann Thorac Surg 2000;69:1670-4.

21 British Thoracic Society and Society of Cardiothoracic Surgeons of Great Britain and Ireland Working Party. Guidelines on the selection of patients with lung cancer for surgery. Thorax 2001;56:89-108.

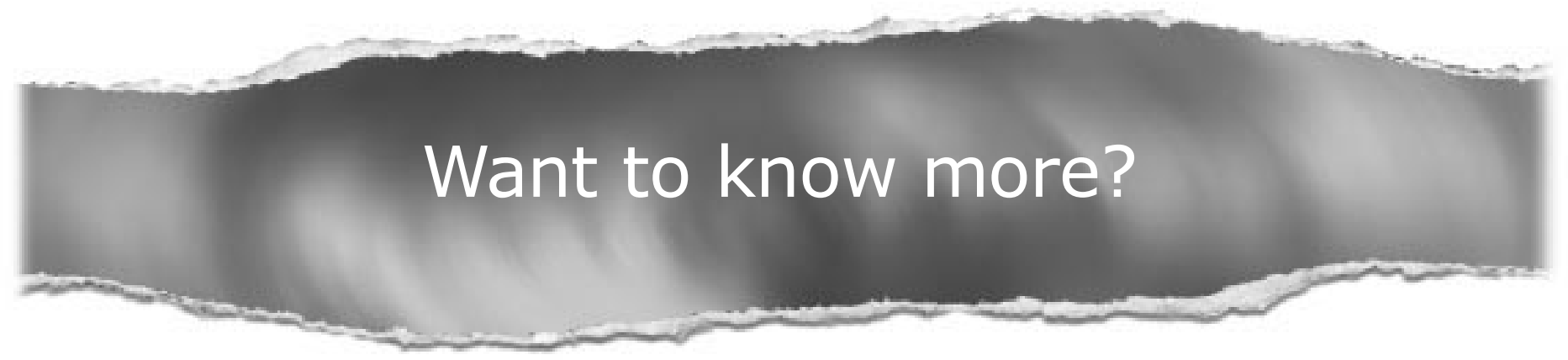

Data supplements

Limited space in printed journals means that interesting data and other material are often edited out of articles; however, limitless cyberspace means that we can include this information online. Look out for additional tables, references, illustrations.

www.thoraxjnl.com 